\title{
A LOOP THERMOSYPHON FOR LIQUID COOLED MINICHANNELS HEAT SINK WITH PULSATE SURFACE HEAT FLUX
}

\author{
Kays A. Al-Tae'y ${ }^{1}$, Ameer Abed Jaddoa ${ }^{1, *}$, Hussain Saad Abd ${ }^{1}$, Riadh Adnan Kadhim ${ }^{1}$
}

\begin{abstract}
The period operation of power electronic acts as switching element, where the power dissipated consists of pulses at certain duty cycle, the semiconductor temperature oscillates and varies as a waveform. In the present study, an experimental investigation was carried out for a loop thermosyphon order to evaluate the effect of pulsate surface heat flux on the single-phase buoyancy driven convection of ethylene glycol flow through a minichannels heat sink with hydraulic diameter $1.5 \mathrm{~mm}$. An electric heater block is used to supply the heat flux to minichannels heat sink in a rectangle waveform. The study is done at different heat flux frequencies of $2.777 \times 10^{-3} \mathrm{~Hz}, 8.333 \times 10^{-4} \mathrm{~Hz}$, $5.555 \times 10^{-4} \mathrm{~Hz}$ and $4.166 \times 10^{-4} \mathrm{~Hz}$, while the heat flux amplitude (2 watt), Rayleigh number (1864) and duty cycle (50 \%) are kept constant. The results revealed that for a range of the measured frequency for the complete power cycle and due to unsteady state operation conditions, the pulse heat flux pattern is close to a rectangle-wave, this generates the fluid outlet temperature pattern close to a triangle-wave. The fluid outlet temperature increases with the decreases of heat flux frequency and tends to reach to the fluid outlet temperature for a constant and continuous heat flux case. Due to closed-loop of thermosyphon, the fluid inlet temperature is changed in pattern like that the fluid outlet temperature change.
\end{abstract}

Keywords: Loop Thermosyphon, Natural Convection, Minichannels Heat Sink, Pulse Heat Flux, SinglePhase Flow, Ethylene Glycol

\section{INTRODUCTION}

Natural convection is an important mechanism for heat transfer equipment used in various cooling systems for electronic devices. The heat flux dissipated from the microprocessor die is mostly non-uniform with concentrated regions of high values and the temperature distribution corresponding to this non-uniformity heat flux. The performance of the microprocessor depends on the temperature (junction temperature), at which it operates; hence the operating temperature of the microprocessor die is always maintained at or less than a maximum design temperature [1]. However, the operation of most electronic devices is strongly influenced by their temperature and their surrounding thermal environment. In some applications, the period operation of semiconductors or power electronic acts as switching element (on-off: switch) or switching frequency, i.e. they are either fully conducting or fully blocking, where the power dissipated (heat generation) in the semiconductor consists of pulses at certain duty cycle, the semiconductors temperature oscillates and varies as a waveform. This temperature oscillation causes additional mechanical stress to the soldering and welding joints inside a semiconductor module and may cause a thermal shock. This leads to an even large temperature oscillation causing thermal shock and fatigue, finally the device fails. Hence, the junction temperature is the limiting condition, and the maximum junction temperature is not excessive $[2,3]$. The electronic components are continuously producing heat when they are running with load or noload operation conditions, but the heat produced with load condition is greater than that produced with no-load condition, so the temperature of electronic components with load condition is greater than at no-load condition [4]. The electronic components undergo with a cyclic change in temperature with time [5]. Many previous researchers studied the cooling systems topic for electronic devices at continuous and constant heat flux (power dissipated), where the effect of power cycle and thermal cycle phenomena is neglected. [4] Experimentally studied the effect of the load operation conditions of $2.8 \mathrm{GHz} \mathrm{CPU}$ chips on the temperature and pressure drop of water flow through rectangular parallel minichannels heat sink with hydraulic diameter $1.6667 \mathrm{~mm}$ and found that the temperature and pressure drop at load are higher than at no-load conditions. [6] Investigated experimentally the cooling system of a loop thermosyphon type. The study consisted of heat transfer testing for four surfaces in the evaporator which were copper-plated, finned, and smooth and blasted. Moreover, four types of working fluids were used in testing process

This paper was recommended for publication in revised form by Regional Editor Ozgen Acikgoz

${ }^{1}$ Department of Electromechanical Engineering, University of Technology, Iraq-Baghdad

${ }^{*}$ E-mail address: 50087@uotechnology.edu.iq

Orcid id: 0000-0003-0433-4465, 0000-0001-5158-1827, 0000-0002-9341-4119

Manuscript Received 09 July 2019, Accepted 29 September 2019 
which was ethanol, R1234ze (Z), R1234ze (E) and R123a. R1234ze (E) performed a better cooling compared with the other working fluids. While, the lowest thermal resistance of boiling was recorded up to $116 \mathrm{~W} / \mathrm{cm}^{2} \mathrm{by} \mathrm{a} \mathrm{blasted}$ surface with the observation of increasing this value drastically with increasing of the heat flux up to $116 \mathrm{~W} / \mathrm{cm}^{2}$. [7] Investigated and compared experimentally two types of squared minichannel heat sinks with the same size projection area and cross section. The first type was straight and sharp $90^{\circ}$ bends at each end, while the second type was spiral. Also, four low viscosities of silicon oils here used in this study in addition to water which were $0.65,1,3$ and $10 \mathrm{cSt}$, for both types as a coolant. As a result, no enhancement in the heat transfer was shown when the viscosity increased, but it was observed that the pumping cost and pressure drop increased. An experimental study was performed by [8] for the effect of the geometry of thermal microsystem (simulating a computer chip) on the flow of water and forced convection heat transfer. A thermal micro system consisted of a heater, parallel microchannels, and inlet and outlet plenum.

Two ways of connecting the parallel microchannels to the inlet and outlet plenum were used; one is perpendicular to the flow direction in the microchannels, and one is same to flow direction in the microchannels. At the range of heat flux, a significant enhancement of heat transfer was found due to flow boiling in microchannels which caused hydraulic instabilities. It was predicted that if the heat flux of heater is uniform (constant), the hydraulic instabilities cause irregularity of electrically heated wall (chip) temperature distribution but at the nonuniform heat flux, the irregularity increased drastically. Hence, in case of hydraulic instability, the two-phase microchannel heat sink loses the heat sink temperature uniformity.

Single-phase forced convection heat transfer through a circular minichannel was experimentally studied at a range of Reynolds numbers $500-4000$ with compressed air as the cooling fluid by [9]. A minichannel tube was made from aluminum with $2 \mathrm{~mm}$ and $3 \mathrm{~mm}$ for the internal and external diameters, respectively. The outcomes showed that the current measurements for the coefficient of heat transfer did not perform very well; therefore additional evaluation devices should be supplied to provide accurate results. [10], experimentally investigated the effect of the imposed pulsations flow rate on the convection heat transfer during the internal single-phase laminar flow through square minichannel under constant heat flux condition and constant average Reynolds number. Cross section size of minichannel is $3 \mathrm{~mm} \times 3 \mathrm{~mm}$. Pulsate frequencies for the flow rate are like a squared and unidirectional waveform is $0.05 \mathrm{~Hz}, 1 \mathrm{~Hz}$ and $3 \mathrm{~Hz}$, but the minimum flow is zero. For laminar pulsating flow case, the improvement in heat transfer was not well if it compared at the same time-average of Reynolds number with steady flow case. As a results, it was concluded that the using of pulsate flow to the enhancement of heat transfer is questionable.

An experimental measured heat transfer performance of a loop thermosyphon using a porous structure on the evaporator surface and a microgroove structure on the condenser surface was evaluated by [11]. The working fluid in the thermosyphon was degassed water. It was concluded that the use of porous and microgroove structure enhanced the heat transfer surfaces performance of that using flat surface.

The effect of reducing fin spacing for minichannels heat sink with water as working fluid on the cooling of microprocessor was investigated by [12]. Five heat sink geometries were tested; four minichannels heat sinks had a varying fin spacing of $0.2 \mathrm{~mm}, 0.5 \mathrm{~mm}, 1.0 \mathrm{~mm}$ and $1.5 \mathrm{~mm}$, while the fifth heat sink had a flat surface for comparison. The fin thickness and height were kept constant at $1.0 \mathrm{~mm}$ and $3 \mathrm{~mm}$, respectively. It was found that the base temperature and thermal resistance of the heat sinks dropped by decreasing the fin spacing and by increasing the volumetric flow rate of water circulating through the heat sink. Also, it was concluded to use nanofluids for enhancement heat transfer capabilities [13], analyzed numerically a three-dimensional minichannel to optimize the thermal and flow characteristic of minichannels heat sink. The flow of water through minichannel is assumed steadystate, single-phase laminar and incompressible. They results indicated that a narrow and deep channel with thin bottom thickness and relatively thin channel wall thickness results in improved heat transfer performance with a relatively high but acceptable pressure drop, and the minichannels heat sink can cool a chip with a heat flux of 256 $\mathrm{W} / \mathrm{cm} 2$ at the pumping power of $0.205 \mathrm{~W}$. Three-dimensional single-phase buoyancy driven convection of water and water based nanofluids was numerically studied in a minichannel heat sink with hydraulic diameter $3.0 \mathrm{~mm}$ was reported by [14]. It was conclude that the buoyancy driven convection of water in minichannel can be employed as reliable cooling method for thermally loaded miniature electronic devices. An experimental investigation was carried out by [15] to find the effect of four shapes of minichannel heat sink which were rectangular, circular, trapezoidal, and square shaped with water as working fluid on the forced convection heat transfer characteristics under steady state condition and constant heat flux. A hydraulic diameter of $2 \mathrm{~mm}$ for all the four types was used. It was found that circular shape of minichannel heat sink gives more rate of heat transfer compared to the other shapes. A pumping power requires for circular shape and rectangular shape of minichannel is maximum and minimum, respectively. Hydrodynamic studies were made by [16] on the topic of flow maldistribution in multiple minichannels heat exchanger. The pressure drops were measured in plate heat exchanger which contains 51 parallel minichannels with a 
rectangular cross section of four hydraulic diameters is $461 \mu \mathrm{m}, 574 \mu \mathrm{m}, 667 \mu \mathrm{m}$, and $750 \mu \mathrm{m}$ connected by trapezoidal inlet and outlet manifold. The authors observed by visualization the flow maldistribution and the channels blockage phenomenon of water single phase flow, and they noticed that the model geometries can work optimally at a range of mass flow rate of $5-8.33 \mathrm{~g} / \mathrm{sec}$ with a range of pressure drops of $600-1250 \mathrm{~Pa}$. Numerically analysis for heat transfer and single-phase fluid flow was done by [17] for the performance evaluation of the effect of nanofluids types in diverging-converging minichannel heat sink. Three types of nanofluids, namely $\mathrm{Al}_{2} \mathrm{O}_{3}-\mathrm{H}_{2} \mathrm{O}, \mathrm{Cu}-\mathrm{H}_{2} \mathrm{O}$, and $\mathrm{SiO}_{2}-\mathrm{H}_{2} \mathrm{O}$ were used. It was found that the nanofluid increased the heat transfer coefficient and is higher in $\mathrm{Al}_{2} \mathrm{O} 3-\mathrm{H}_{2} \mathrm{O}$ followed by $\mathrm{SiO}_{2}-\mathrm{H}_{2} \mathrm{O}$ and $\mathrm{Cu}-\mathrm{H}_{2} \mathrm{O}$.

Analytically analysis for free convection flow occurring about a heated permeable vertically stretching surface placed in a porous medium by [18] under the influence of a temperature dependent internal heat generation or absorption flux. The analysis is conducted in the presence of radiative heat sources in the fluid while the system is permeated by a uniform magnetic field. The exact solutions are found, in the presence of a heat sink absorbing the temperature from the medium increases the rate of heat transfer from the wall, whereas a heat source will surely heat up the system under consideration, resulting in poorer heat transfer rates.

From the above literature review, it is revealed that researchers have used minichannels heat sink with constant heat flux at the bottom surface to reduce the electronic devices temperature to design temperature. No attempt has been made to investigate the heat flux in the electronic devices consisting of pulses at certain duty cycle, where the semiconductors heat generation oscillates and varies as a waveform. In the present study, an attempt has been made to investigate the effect of heat flux oscillation on the single-phase buoyancy driven convection of ethylene glycol flow through a minichannel heat sink with hydraulic diameter $1.5 \mathrm{~mm}$. An electric heater block will be used to supply the heat flux to minichannels in a rectangle waveform, where the heat flux is 2.0 watt or 0.0 watt, to simulate the heat generating by electronic devices. The maximum power supply by electric heater is 2 watt for a safe operating value of single-phase temperature

\section{EXPERIMENTAL SETUP \\ MINICHANNELS HEAT SINK}

The minichannels heat sink as shown in Figure 1(a) was manufactured from copper 360 alloy, with dimensions $34 \mathrm{~mm} \times 33 \mathrm{~mm}$ and $5 \mathrm{~mm}$ thickness. A minichannels heat sink includes the uniform arrays of 17 fins and 16 channels, a channel design of rectangular cross section with hydraulic diameter $1.5 \mathrm{~mm}$. A channel width, height and thickness, and all other dimensions are shown in Figure 1(b) and given in Table 1.

The minichannels heat sink is centered inside Plexiglas enclosure with one inlet and outlet manifolds for distribution and collection of ethylene glycol liquid that entering and leaving to and from minichannels, respectively. One cartridge heater inserted in the heating block generates the heat load to the minichannels and then transfers that heat to the ethylene glycol $(\mathrm{Pr}=150)$ flow through the channels of minichannels. A heater is providing $2 \mathrm{~W}$ of total power. The heat is providing by a variable power supply monitored by a digital watt meter. An electric heater block is attached upward to the bottom of the evaporator through thermal grease to minimize the interface resistance. The thermal grease used is silicon paste type AOS Silicone XT white paste.

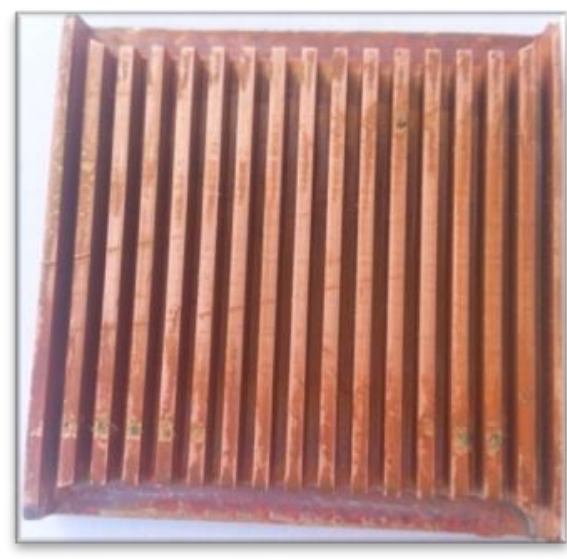

a)

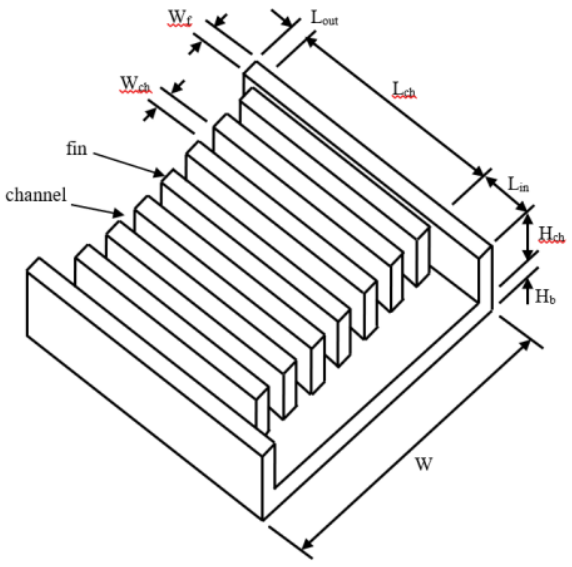

b)

Figure 1. a) Minichannels heat sink component, b) schematic view of the minichannel geometry for heat flux cooling application (not drawn in actual scale or proportions) 
Table 1. Dimensions of minichannels heat sink

\begin{tabular}{|l|c|c|}
\hline \multicolumn{1}{|c|}{ Description } & Symbol & Value \\
\hline Width of channel & $\mathrm{W}_{\mathrm{ch}}$ & $1 \mathrm{~mm}$ \\
\hline Length of channel & $\mathrm{L}_{\mathrm{ch}}$ & $34 \mathrm{~mm}$ \\
\hline Height of channel & $\mathrm{H}_{\mathrm{ch}}$ & $3 \mathrm{~mm}$ \\
\hline Thickness of fins & $\mathrm{W}_{\mathrm{f}}$ & $1 \mathrm{~mm}$ \\
\hline Un-finned length of heat sink; inlet manifold & $\mathrm{L}_{\mathrm{in}}$ & $3 \mathrm{~mm}$ \\
\hline Un-finned length of heat sink; outlet manifold & $\mathrm{L}_{\text {out }}$ & $3 \mathrm{~mm}$ \\
\hline Thickness of heat sink base plat & $\mathrm{H}_{\mathrm{b}}$ & $2 \mathrm{~mm}$ \\
\hline Width of finned section on heat sink & $\mathrm{W}$ & $33 \mathrm{~mm}$ \\
\hline Hydraulic diameter & $\mathrm{D}_{\mathrm{h}}$ & $1.5 \mathrm{~mm}$ \\
\hline Number of channels & $\mathrm{N}_{\mathrm{ch}}$ & 16 \\
\hline Number of fins & $\mathrm{N}_{\mathrm{f}}$ & 17 \\
\hline
\end{tabular}

\section{EXPEREMNTAL TEST RIG}

A schematic diagram of experimental device is shown in Figure 2(a). This closed - loop system composed mainly of a vertical minichannels heat sink component as illustrated in Figure 2(b), a rising tube, a reservoir with injection tube, air cooled condenser and a falling tube. The operating principle is as follows: the liquid of the ethylene glycol is heated in the minichannels by the heat load that is generating by the electrical heater. After that, the heated liquid of the ethylene glycol rises along a vertical tube or a rising tube and enters a reservoir. A small tube attaches to the reservoir, called the injection tube, and is used to inject ethylene glycol liquid. Then, the ethylene glycol liquid leaves the reservoir to the condenser. At the condenser, the temperature of liquid decrease by losing heat to the cooling air flow into the condenser. Then, the liquid from the condenser returns to the minichannels component by the falling tube due to gravity.

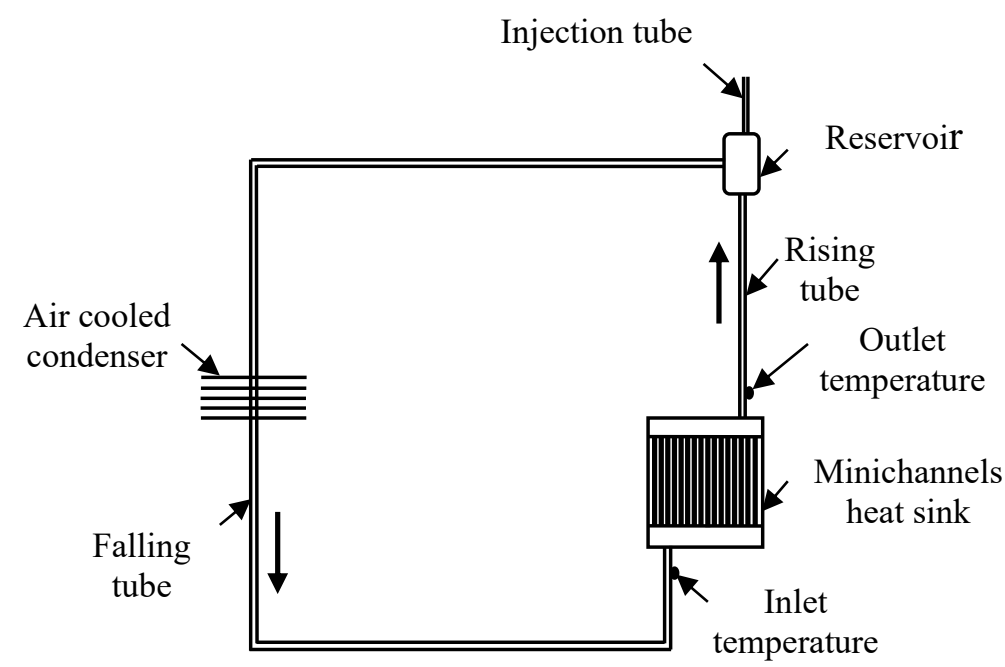

a)

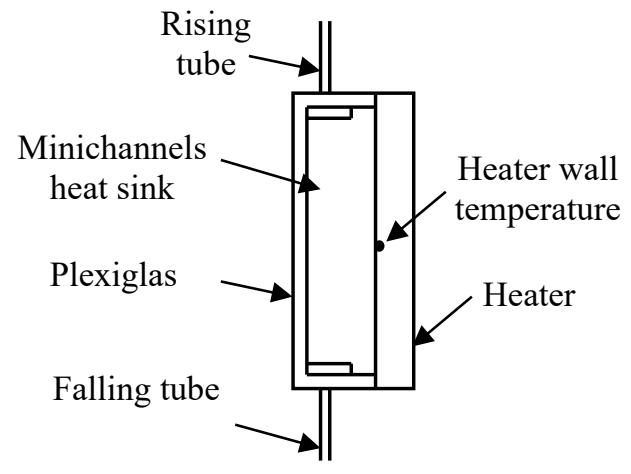

b)

Figure 2. a) The overall schematic of experimental arrangement, b) minichannels heat sink with heater assembly

The working fluid charging into the experimental apparatus is through injection tube. Temperature of heating block, inlet and outlet ethylene glycol to and from the minichannels heat sink component, respectively and 
ambient air were measured using calibrated type $\mathrm{T}$ thermocouples, as illustrated in Figure 2. The power consumption of heater was measured by using the input electric voltage and current (V: $10-0$ volt and I: $0.2-0$ amp) and took this as the amount of input heating at constant heat flux thermal boundary condition. The imposed heat flux pulsations are created by electronically controlled power supply on-off switch of electric heater. The pulsed heat flux (q: $2-0 \mathrm{watt}$ ) is generated by alternately opening the power supply switch, i.e. there will be a power supply (V=10 volt, $\mathrm{I}=0.2 \mathrm{amp}$, and $\mathrm{q}=2 \mathrm{watt})$ in the electrical heater for a half of time period and no power supply $(\mathrm{V}=0$ volt, $\mathrm{I}$ $=0 \mathrm{amp}$, and $\mathrm{q}=0 \mathrm{watt}$ ) in the next half of the time period. Thus, the heat flux supply by the electrical heater to minichannels will result in a rectangle waveform. In this research, four imposed surface heat flux frequencies were used as illustrated in Table 2, and in all the experiments, the maximum and minimum surface heat flux amplitude is 2 watt and 0 watt, respectively. The average Rayleigh number of the natural convection, at all the imposed frequencies, was fixed at 1864 .

Table 2. properties of pulse repetition surface heat flux

\begin{tabular}{|c|c|c|c|c|}
\hline \multirow{2}{*}{ case } & \multicolumn{2}{|c|}{ time periodic for pulse repetition surface heat flux } & $\begin{array}{c}\text { pulsation } \\
\text { frequency } \mathbf{~ H z}\end{array}$ & $\begin{array}{c}\text { pulse } \\
\text { duty } \\
\text { cycle }\end{array}$ \\
\hline $\mathrm{b}$ & $3 \mathrm{~min}$ & $3 \mathrm{~min}$ & $2.777 \times 10^{-3}$ & $50 \%$ \\
\hline $\mathrm{c}$ & $10 \mathrm{~min}$ & $10 \mathrm{~min}$ & $8.333 \times 10^{-4}$ & $50 \%$ \\
\hline $\mathrm{d}$ & $15 \mathrm{~min}$ & $15 \mathrm{~min}$ & $5.555 \times 10^{-4}$ & $50 \%$ \\
\hline $\mathrm{e}$ & $20 \mathrm{~min}$ & $20 \mathrm{~min}$ & $4.166 \times 10^{-4}$ & $50 \%$ \\
\hline
\end{tabular}

\section{RESULTS AND DISCUSSION}

The present study is done at four different pulsating heat flux frequencies and compares these with a constant and continuous heat flux, case (a), as illustrated in Table 2 and Figure 3. A single-phase ethylene glycol flow in parallel minichannels is period oscillating according to the imposed heat flux pulsated.

The waveform of instantaneous heat flux and the corresponding variation of ethylene glycol temperature at inlet and outlet of the minichannels are shown in Figure 3 and Figure 4, respectively, for the applied constant and period heat flux at frequencies of $\mathrm{f}=2.777 \times 10^{-3} \mathrm{~Hz}, 8.333 \times 10^{-4} \mathrm{~Hz}, 5.555 \times 10^{-4} \mathrm{~Hz}$ and $4.166 \times 10^{-4} \mathrm{~Hz}$, respectively. It can be observed that the waveform pattern of the heat flux and temperature is close to a rectangle- and trianglewave, respectively. For the complete power cycle, heat flux or heat generation takes place for a half of the cycle, oncycle, and no heat generation occurs in the other half of cycle, off-cycle. Due to such type of imposed heat flux pulsations, the ethylene glycol temperature at any location in minichannels oscillates in a periodic manner, increasing in the on-cycle and decreasing in the off-cycle. The time duration, and hence the heat flux frequency of the on-cycle and the off-cycle are controlled by on-off power electric supply switch arrangement.

During the on-cycle of power cycle, the flow induced through the channels by buoyancy force. The buoyancy driven convection dominates and exists through the complete power cycle due to the temperature difference between inlet fluid and heat flux of heater wall.

For the complete power cycle, and at high operation frequency, less time is available for heating the fluid during the on-cycle time, as seen from Table 2. This is clearly seen in Figure 3(b) and Figure 4(b), where, as the halftime of period of oscillation is $180 \mathrm{sec}$, there is insufficient time when the on-cycle conditions exist in the channel and hence, insignificant amount of heat is conducted to the fluid by the heat flux heater wall which eventually increases its temperature.

At low operation frequency, the oscillating amplitude of the local inlet and outlet temperature of the fluid and the heater wall temperature increases due to its higher residence time of power supply during on-cycle, and the oscillating of outlet fluid temperature causes oscillating in the inlet fluid temperature due to the fixed air temperature (approximately $30^{\circ} \mathrm{C}$ ) used to cool the fluid flow through the condenser of loop thermosyphon as can be seen in Figure 4(b), (c) and (d). 
Journal of Thermal Engineering, Technical Note, Vol. 7, No. 4, pp. 1030-1038, May, 2021

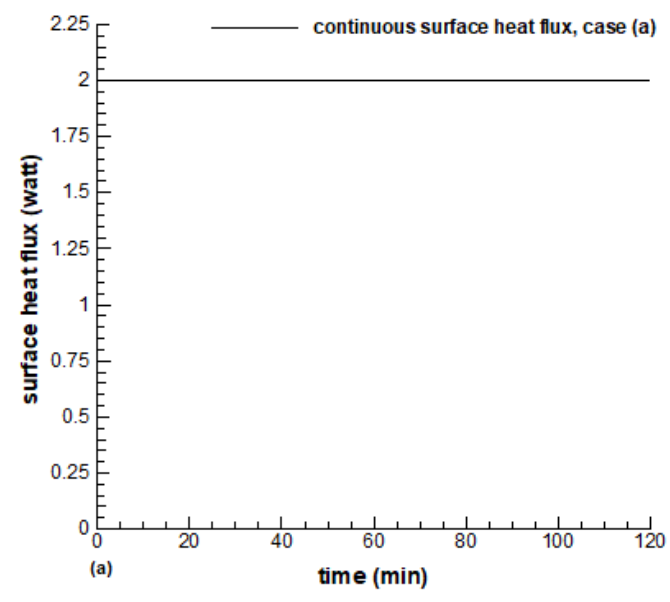

a) Constant and continuous heat flux case

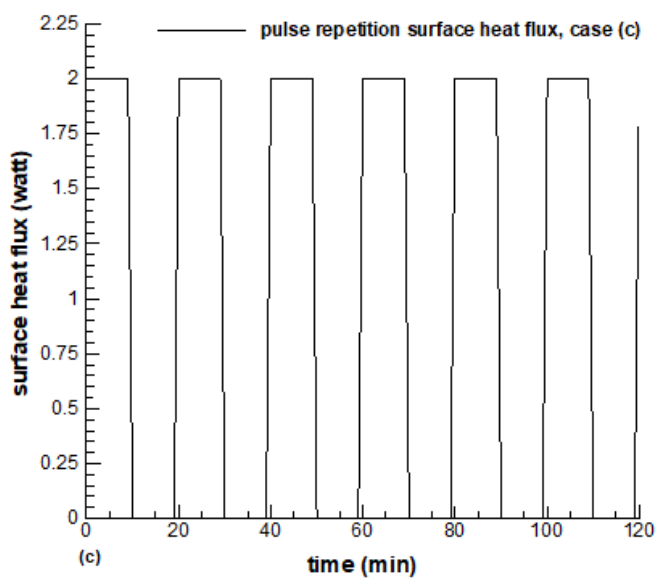

c) Pulse repetition heat flux at frequency $8.333 \times 10^{-4} \mathrm{~Hz}$ and duty cycle $50 \%$

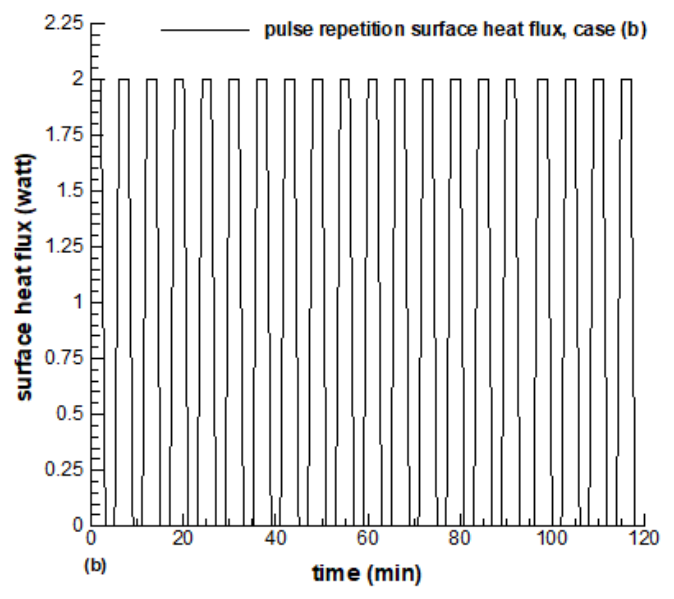

b) Pulse repetition heat flux at frequency $2.777 \times 10^{-3} \mathrm{~Hz}$ and duty cycle $50 \%$

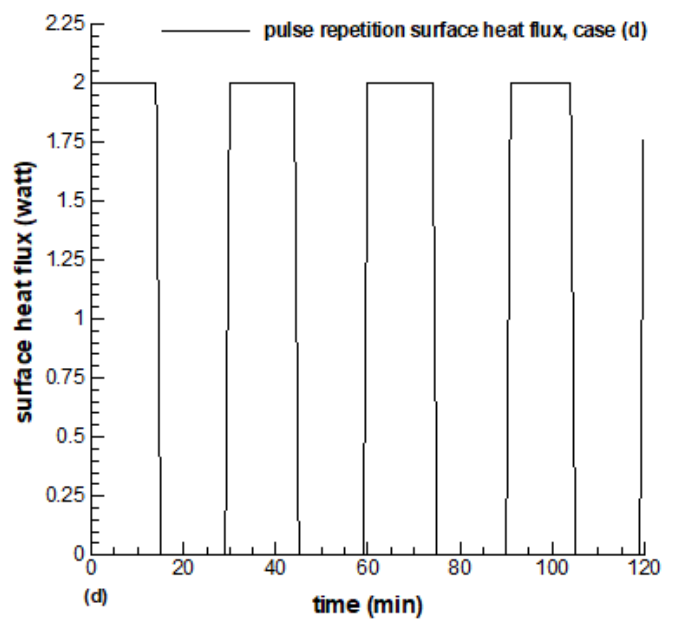

d) Pulse repetition heat flux at frequency $5.555 \times 10^{-4} \mathrm{~Hz}$ and duty cycle $50 \%$

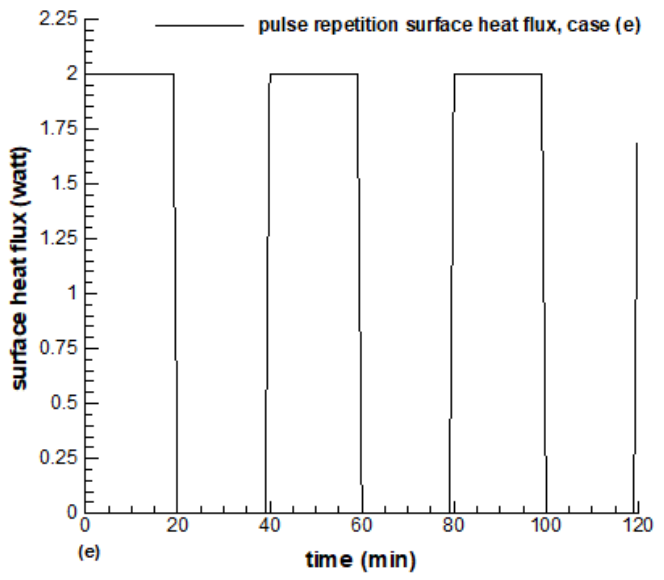

e) Pulse repetition heat flux at frequency $4.166 \times 10^{-4} \mathrm{~Hz}$ and duty cycle $50 \%$

Figure 3. Variation of surface heat flux with time 


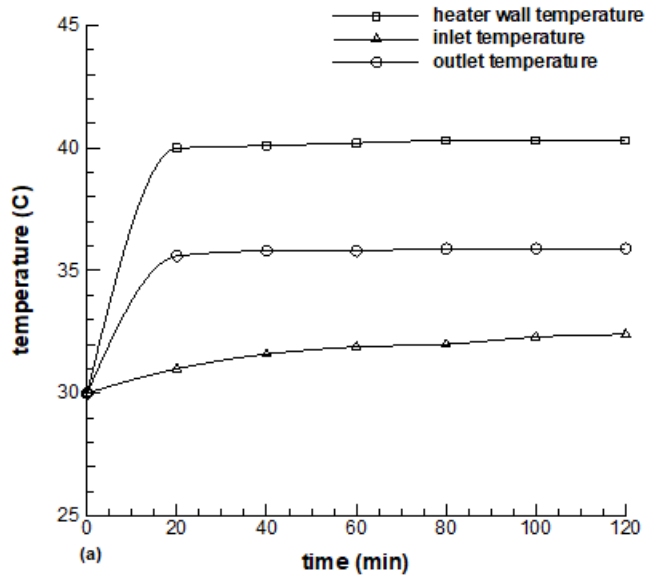

a) Constant and continuous heat flux case

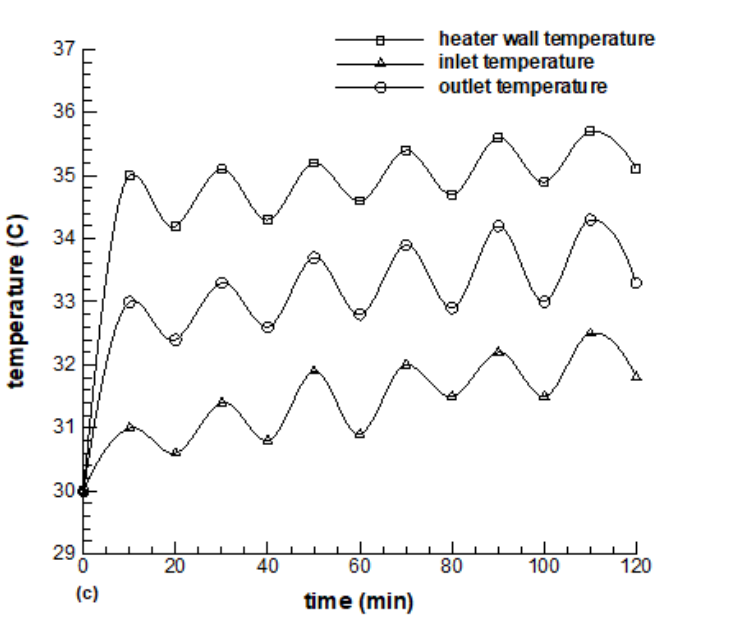

c) Pulse repetition heat flux at frequency $8.333 \times 10^{-4} \mathrm{~Hz}$ and duty cycle $50 \%$

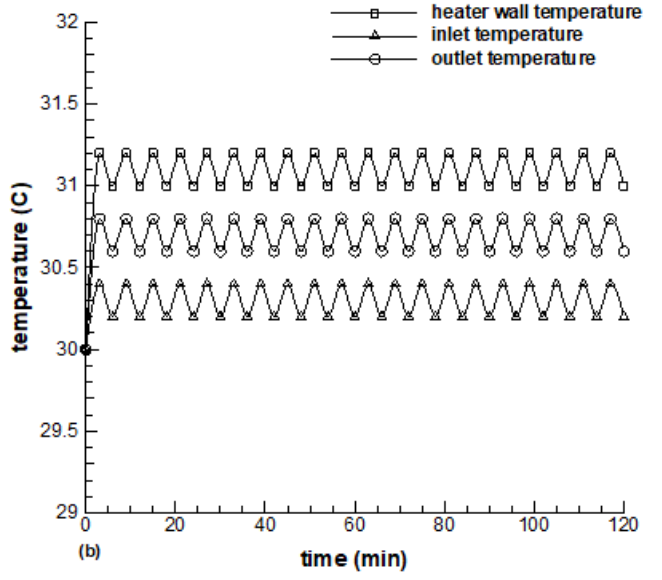

b) Pulse repetition heat flux at frequency $2.777 \times 10^{-3} \mathrm{~Hz}$ and duty cycle $50 \%$

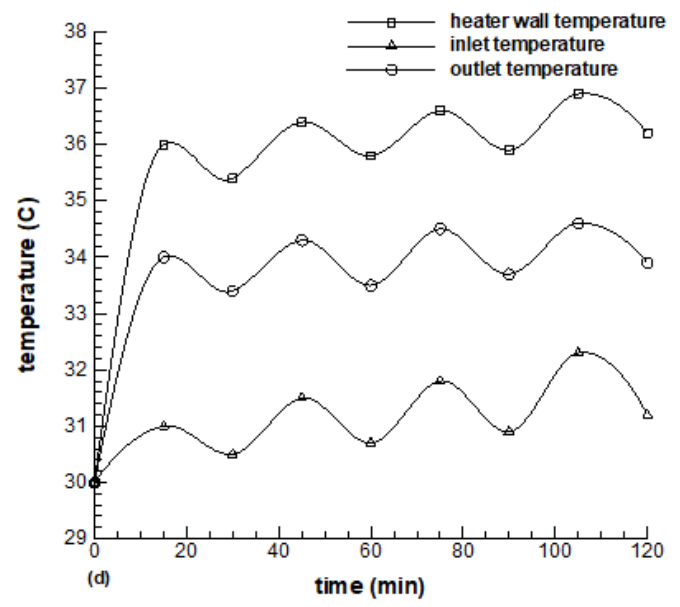

d) Pulse repetition heat flux at frequency $5.555 \times 10^{-4} \mathrm{~Hz}$ and duty cycle $50 \%$

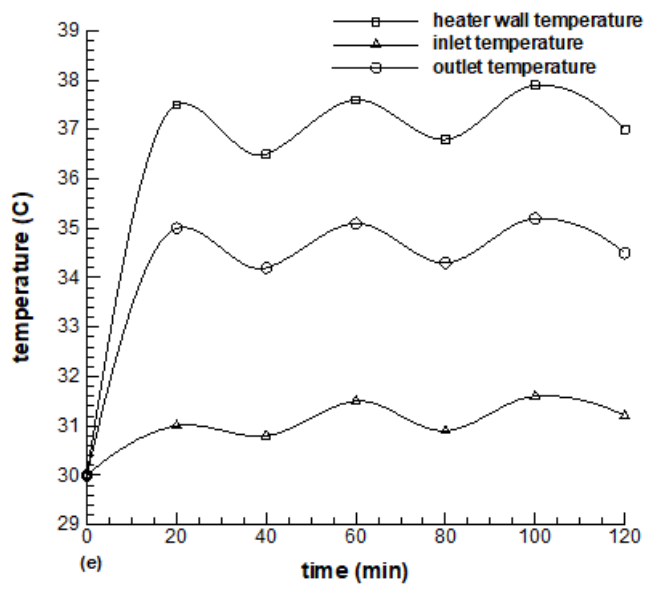

e) Pulse repetition heat flux at frequency $4.166 \times 10^{-4} \mathrm{~Hz}$ and duty cycle $50 \%$

Figure 4. Waveform illustrating that maximum temperature of ethylene glycol is a function of switching frequency 
The fluid outlet temperature increases with the decrease of heat flux frequency and tends to reach to fluid outlet temperature for a constant and continuous heat flux case, Figure 4(a). When the imposed frequency increases, the periodic for heating the heater wall and fluid decreases as can be seen in Figure 5(a) and (b), respectively. Hence, the heat flux pulses didn't cause the temperature of heater (or chip) to become equal or over the maximum design temperature, but the temperature oscillations due to the heat flux pulsates cause a mechanical stress to the bond-wire welding of silicon chip and then increase the voltage drop, this leads to large temperature oscillation and finally the device fails [2]. The structured fluctuation patterns of inlet, outlet and heater wall temperature for the same case are approximated similar to each other and appeared the characteristic frequency due to the disturbances created by the imposed pulsation which effect actually on the buoyancy force that driven the convection of fluid.

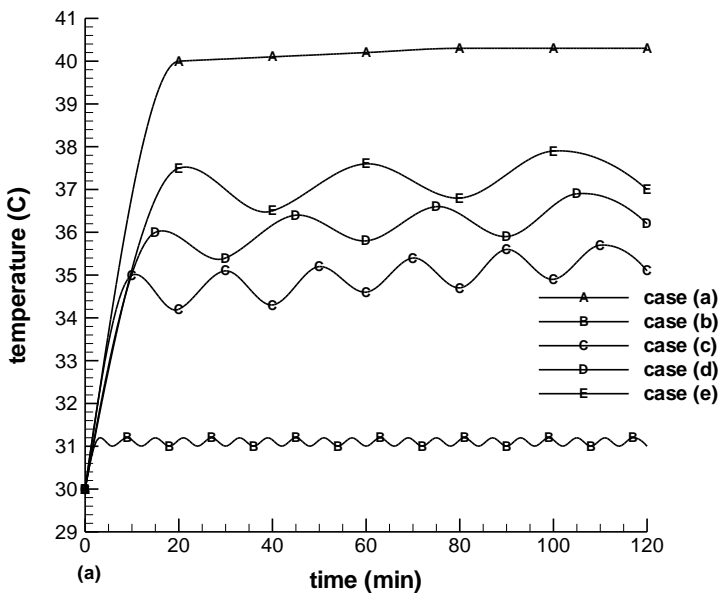

a)

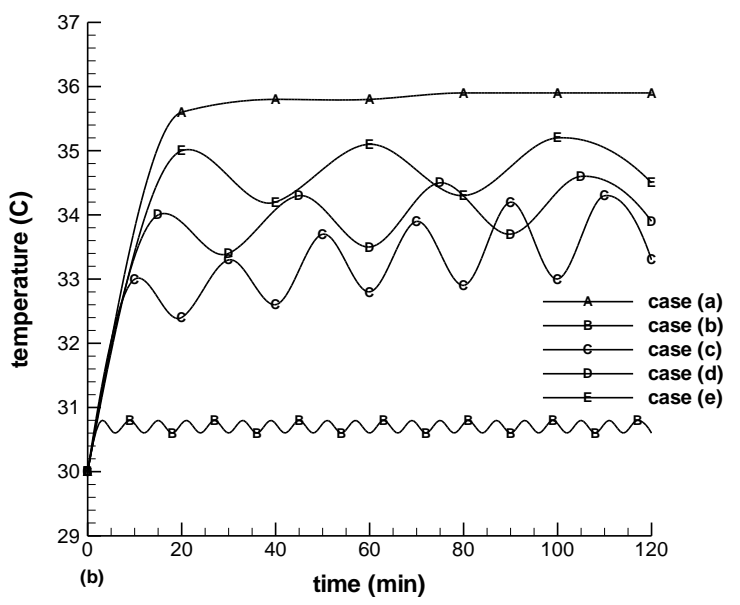

b)

Figure 5. Comparison between maximum temperatures of ethylene glycol for different cases of surface heat flux; a) heater wall temperature: b) outlet temperature

\section{SUMMARY AND CONCLUSIONS}

The loop thermosyphon type cooling system was investigated experimentally in order to evaluate the effect of pulsating heat flux on the buoyancy driven laminar single-phase flow and convection heat transfer of ethylene glycol $(\mathrm{Pr}=150)$ through a minichannels heat sink. Four different heat flux frequencies of $2.777 \times 10^{-3} \mathrm{~Hz}, 8.333 \times$ $10^{-4} \mathrm{~Hz}, 5.555 \times 10^{-4} \mathrm{~Hz}$ and $4.166 \times 10^{-4} \mathrm{~Hz}$ with a constant and continuous heat flux case were used. The heat flux amplitude (2 watt), Rayleigh number (1864) and duty cycle (50\%) are kept constant. The major conclusions of the study are as follows:

- The experimental data predicted that the case of a constant and continuous heat flux has a maximum heater wall temperature (simulated to chip) and fluid outlet temperature.

- For the complete power cycle and due to unsteady state operation conditions, the pulse heat flux pattern is close to a rectangle-wave and this made the fluid outlet temperature pattern close to a triangle-wave.

- At high operation frequency, less time is available for heating the fluid during the on-cycle time, and then insignificant amount of heat is conducted to the fluid by the heat flux heater wall. But at low operation frequency, the oscillating amplitude of the local outlet temperature of the fluid and the heater wall temperature increases due to it is higher residence time of power supply during on-cycle.

- Due to the closed-loop of thermosyphon, the fluid inlet temperature was changing in pattern like that the fluid outlet temperature change.

- In general, the fluid outlet temperature increases with the decreases of heat flux frequency and tends to reach to the fluid outlet temperature for a constant and continuous heat flux case. 
Journal of Thermal Engineering, Technical Note, Vol. 7, No. 4, pp. 1030-1038, May, 2021

\section{REFERENCES}

[1] Jha, Chandra Mohan. Thermal Sensors Principles and Applications for Semiconductor Industries. Principles of Chemical Sensors, 2009. https://doi.org/10.1007/b136378_3.

[2] Künzi, R. Thermal Design of Power Electronic Circuits. In CERN Accelerator School: Power Converters, CAS 2014 - Proceedings, 2018;311-327. https://doi.org/10.5170/CERN-2015-003.311.

[3] Miller, T.J.E. Power Electronics Devices, Drivers and Applications. Electronics and Power, 1987. https://doi.org/10.1049/ep.1987.0287.

[4] Al-Tae'y, K. A. , Eqbal H.A. and Jebur M. N. Experimental investigation of water cooled minichannel heat sink for computer processing unit cooling, Int. Journal of Engineering Research and Application, 2017; 3849. https:// doi.org/10.9790/9622-0708013849

[5] Mallik, Sabuj, and Franziska Kaiser. Reliability Study of Subsea Electronic Systems Subjected to Accelerated Thermal Cycle Ageing. In Lecture Notes in Engineering and Computer Science, 2014. https://gala.gre.ac.uk/id/eprint/12319/.

[6] Yeo, Jiwon, Seiya Yamashita, Mizuki Hayashida, and Shigeru Koyama. A Loop Thermosyphon Type Cooling System for High Heat Flux. Journal of Electronics Cooling and Thermal Control, 2014;128-137. https://doi.org/10.4236/jectc.2014.44014.

[7] Ghobadi, Mehdi, and Yuri S. Muzychka. Heat Transfer and Pressure Drop in Mini Channel Heat Sinks. Heat Transfer Engineering, 2015;902-911. https://doi.org/10.1080/01457632.2015.965097.

[8] Hetsroni, G., A. Mosyak, and Z. Segal. Nonuniform Temperature Distribution in Electronic Devices Cooled by Flow in Parallel Microchannels. IEEE Transactions on Components and Packaging Technologies, 2001;16-23. https://doi.org/10.1109/6144.910797.

[9] Hejcik, Jiri, and Miroslav Jicha. Single Phase Heat Transfer in Minichannels. In EPJ Web of Conferences, 2014. https://doi.org/10.1051/epjconf/20146702034.

[10] Mehta, Balkrishna, and Sameer Khandekar. Local Experimental Heat Transfer of Single-Phase Pulsating Laminar Flow in a Square Mini-Channel. International Journal of Thermal Sciences, 2015;157-166. https://doi.org/10.1016/j.ijthermalsci.2015.01.008.

[11] Toyoda, Hiroyuki, and Yoshihiro Kondo. Heat Transfer Performance of Loop Thermosyphon Using Enhanced Boiling and Condensation Surfaces. Transaction on Control and Mechanical Systems, 2013;432435.

[12] Jajja, Saad Ayub, Wajahat Ali, Hafiz Muhammad Ali, and Aysha Maryam Ali. Water Cooled Minichannel Heat Sinks for Microprocessor Cooling: Effect of Fin Spacing. Applied Thermal Engineering, 2014;76-82. https://doi.org/10.1016/j.applthermaleng.2013.12.007.

[13] Xie, X. L., Z. J. Liu, Y. L. He, and W. Q. Tao. Numerical Study of Laminar Heat Transfer and Pressure Drop Characteristics in a Water-Cooled Minichannel Heat Sink. Applied Thermal Engineering, 2009;64-74. https://doi.org/10.1016/j.applthermaleng.2008.02.002.

[14] Joseph, A. and Rajkumar, M. R. A numerical study on natural convection in mini channel using water and water- alumina nanofluid, 10th National Conference on Technological Trends, 2009, pp. 119-124.

[15] Asif, A., Samee, M. and Khanm S. A.,. Comparative heat transfer analysis in different minichannel heat sinks, International Journal of Recent Research, 2017, pp. 41-45.

[16] Dabrowski, Pawel, Michal Klugmann, and Dariusz Mikielewicz. Selected Studies of Flow Maldistribution in a Minichannel Plate Heat Exchanger. Archives of Thermodynamics, 2017;135-148. https://doi.org/10.1515/aoter-2017-0020

[17] Muhammad, Nura Mu'Az, Nor Azwadi Che Sidik, Aminuddin Saat, and Bala Abdullahi. Effect of Nanofluids on Heat Transfer and Pressure Drop Characteristics of Diverging-Converging Minichannel Heat Sink. CFD Letters, 2019;104-119.

[18] Turkyilmazoglu, M. "MHD Natural Convection in Saturated Porous Media with Heat Generation/Absorption and Thermal Radiation: Closed-Form Solutions." Archives of Mechanics, 2019;49-64. https://doi.org/10.24423/aom.3049. 